\title{
Enzymatic synthesis of sugar esters and their potential as surface-active stabilizers of coconut milk emulsions
}

\author{
Nair do Amaral Sampaio Neta ${ }^{a}$, José Cleiton Sousa dos Santos ${ }^{b}$, Soraya de Oliveira Sancho ${ }^{c}$, \\ Sueli Rodrigues ${ }^{c}$, Luciana Rocha Barros Gonçalves ${ }^{\mathrm{b}, *}$, Ligia R. Rodrigues ${ }^{\mathrm{a}}$, José A. Teixeira ${ }^{\mathrm{a}}$ \\ a IBB, Institute for Biotechnology and Bioengineering, Department of Biological Engineering, Centre of Biological Engineering, Universidade do Minho, 4710-057 Braga, Portugal \\ ${ }^{\mathrm{b}}$ Department of Chemical Engineering, Federal University of Ceará, Campus of Pici, Block 709, 60455-760 Fortaleza, Ceará, Brazil \\ ${ }^{c}$ Department of Food Technology, Biotechnology Laboratory, Federal University of Ceará, Campus of Pici, Block 851, 60455-760 Fortaleza, Ceará, Brazil
}

\section{A R T I C L E I N F O}

\section{Article history:}

Received 27 March 2011

Accepted 12 October 2011

\section{Keywords:}

Sugar esters

Chitosan

Acrylic resin

Yield

Emulsifier

Esterification

\begin{abstract}
A B S T R A C T
Sugar esters are compounds with surfactant properties (biosurfactants), i.e., capable of reducing the surface tension and promote the emulsification of immiscible liquids. On the other hand, as with all emulsions, coconut milk is not physically stable and is prone to phase separation. Therefore, the aim of this work was to evaluate the synthesis of fructose, sucrose and lactose esters from the corresponding sugars using Candida antarctica type B lipase immobilized in two different supports, namely acrylic resin and chitosan, and evaluate its application in the stabilization of coconut milk emulsions. The enzyme immobilized on chitosan showed the highest yield of lactose ester production (84.1\%). Additionally, the production of fructose ester was found to be higher for the enzyme immobilized on the acrylic resin support (74.3\%) as compared with the one immobilized on chitosan (70.1\%). The same trend was observed for the sucrose ester, although with lower percentage yields. Sugar esters were then added to samples of fresh coconut milk and characterized according to their surface tension, emulsification index and particle size distribution. Although the microscopic analysis showed similar results for all sugar esters, results indicated lactose ester as the best biosurfactant, with a surface tension of $38.0 \mathrm{~N} / \mathrm{m}$ and an emulsification index of $54.1 \%$, when used in a ratio of $1: 10$ (biosurfactant:coconut milk, v/v) for $48 \mathrm{~h}$ experiments.
\end{abstract}

(c) 2011 Elsevier Ltd. All rights reserved.

\section{Introduction}

Many tropical countries use coconut milk, an oil-in-water emulsion formed from the aqueous extract of coconut (Cocos nucifera, LINNAEUS) solid endosperm, as an ingredient in cooking (Tangsuphoom \& Coupland, 2009a). Those emulsions are thermodynamically unstable because of the unfavorable contact between oil and water molecules. Therefore, their physical structures will tend to change over time by various mechanisms (creaming, flocculation, and coalescence), which may cause the complete phase separation (Tangsuphoom \& Coupland, 2008). Furthermore, the emulsion is relatively unstable because of the large droplet size and the poor emulsifying properties of coconut proteins adsorbed at the oil-water interface. According to the literature (Tangsuphoom \& Coupland, 2005, 2009a,b), more stable products may be achieved by adding proteins or small-molecule surfactants during

\footnotetext{
* Corresponding author. Tel.: +55 85 33669611; fax: +55 8533669610 .

E-mail address: lrg@ufc.br (L.R.B. Gonçalves).
}

manufacturing and the stabilized coconut milk is preserved by chilling, freezing, pasteurization, or sterilization. Several authors studied the role of native coconut proteins on the stability of coconut milk (Jena \& Das, 2006; Jirapeangtong, Siriwatanayothin, \& Chiewchan, 2008; Onsaard, Vittayanont, Srigam, \& McClements, 2005; Tangsuphoom \& Coupland, 2008) and they observed that they were not able to stabilize it sufficiently against creaming during storage. Onsaard et al. (2005) related that coconut protein fractions can be used to prepare oil-in-water emulsions, but they were not able to create stable emulsions. Those authors also state that native coconut proteins are most effective at stabilizing viscous emulsions, where droplet flocculation and creaming are not a major problem. Based on the previous findings, in this work, the use of biosurfactants, namely fructose, sucrose and lactose esters, was investigated.

The environmental concern about chemical surfactants is promoting the investigation on the use of biosurfactants to replace products that are already in use in the food industry. Some properties that can be explored are: emulsion forming and stabilization, antiadhesive and antimicrobial activities, low toxicity and 
biodegradability (Chamouleau, Coulon, Girardin, \& Ghoul, 2001; Nitschke \& Costa, 2007; Park et al., 2004; Tsavas et al., 2002).

Nonionic biosurfactants, such as sugar fatty acid esters, may be obtained by enzymatic synthesis, a new manufacturing method for future application in food, cosmetic, detergent, and pharmaceutical industry. Fructose monoesters synthesized by lipases, for instance, are used as antibacterial agents applicable to food additives (Sabeder, Habulin, \& Knez, 2005). They may be produced from renewable and inexpensive substances under mild reaction conditions, which minimize side reactions compared to the chemical process (Sabeder, Habulin, \& Knez, 2006; Ye, Pyo, \& Hayes, 2010).

Therefore, the aim of this work was to investigate enzymatic production of sugar esters (biosurfactants) using Candida antarctica lipase type B immobilized in acrylic resin (commercial) or chitosan as supports. Additionally, the sugar esters were characterized according to their ability to stabilize coconut milk.

\section{Materials and methods}

\subsection{Materials}

All chemicals used were analytical grade. Commercial coconut milk was purchased from a local market (Fortaleza-CE, Brazil); the triacylglycerol lipase purified from $C$. antartica B immobilized in acrylic resin (CALB) (Novozym 435) was purchased from SigmaAldrich (Sigma-Aldrich Co., St. Louis, MO); powdered chitosan, 85.2\% deacetylation degree was purchased from Polymar Ind Ltd. (Fortaleza - CE, Brazil); and type B native soluble lipase B from C. antarctica (Lipozyme ${ }^{\circledR}$ CALB L) was kindly provided by Novozymes Latin America Ltd. (Araucária, Brazil).

\subsection{Methods}

\subsubsection{Preparation and activation of the immobilization support}

In this work, chitosan was used as a solid support for soluble lipase (type B from $C$. antarctica) immobilization, based on the methodology described by Rodrigues, Mendes, Adriano, Gonçalves, and Giordano (2008). Briefly, $4.0 \mathrm{~g}$ of powdered chitosan was added to $96.0 \mathrm{~mL}$ of a $5 \%$ acetic acid solution. The obtained solution was dropped into a gently stirred $1 \mathrm{M} \mathrm{NaOH}$ solution for $24 \mathrm{~h}$, at room temperature. Afterward, it was washed with an excess of distilled water.

The support was activated with glycidol, ethylenediamine (EDA) and glutaraldehyde. Activation of chitosan with glycidol was carried out by etherification and further oxidation with sodium periodate (Guisán, 1988), $10 \mathrm{~g}$ of Chitosan-Glyoxyl gel was reacted with $40 \mathrm{~mL}$ of a $2 \mathrm{M}$ ethylenediamine solution, $\mathrm{pH} 10.0$ (Cardias, Grininger, Trevisan, Guisan, \& Giordano, 1999). Finally, $9 \mathrm{~mL}$ of sodium bicarbonate buffer, $\mathrm{pH} 10.0$, containing $5 \%(\mathrm{v} / \mathrm{v})$ of glutaraldehyde, was added to $1 \mathrm{~g}$ of chitosan-Glyoxyl-EDA. The mixture was kept under agitation for $60 \mathrm{~min}$ at $25^{\circ} \mathrm{C}$. After this time, supports were washed with distilled water to remove the excess of activating agent.

\subsubsection{Immobilization of $C A L B$}

Soluble lipase (type B from $C$. antarctica) was immobilized on chitosan gels, after activation with glycidol, ethylenediamine and glutaraldehyde. The immobilization was carried out in $100 \mathrm{mM}$ bicarbonate buffer, $\mathrm{pH} 10.05$, at $25^{\circ} \mathrm{C}$ and $5 \mathrm{~h}$, under gentle stirring. In the immobilization assays, $109 \mathrm{U}$ (hydrolytic activity) per gram of support was used.

\subsubsection{Lipase activity}

The hydrolytic activity of soluble and immobilized CALB was determined according to a methodology described in literature
(Bhatnagar et al., 2005), with some modifications. The product, $p$-nitrophenol, released during the hydrolysis of $p$-nitrophenyl butyrate (pNPB), yielded a colored product, measured at $410 \mathrm{~nm}$. A working substrate solution was prepared by adding $1 \mathrm{~mL}$ of $15 \mathrm{mM} \mathrm{pNPB}$, in 2-propanol, to $29 \mathrm{~mL}$ of $25 \mathrm{mM}$ sodium phosphate at $\mathrm{pH}$ 7. To determine soluble enzyme activity, the reaction was initiated by adding $0.2 \mathrm{~mL}$ of enzyme solution to $2.8 \mathrm{~mL}$ of the working substrate solution. The immobilized enzyme activity was measured by adding $2 \mathrm{~g}$ of immobilized enzyme to $28 \mathrm{~mL}$ of the working solution. In both cases, the rate of hydrolysis was monitored at $410 \mathrm{~nm}$ and $25^{\circ} \mathrm{C}$ in a spectrophotometer (Biochrom Libra S22, UK) against a blank without enzyme. In this work, one unit (U) of enzymatic activity was defined as the amount of enzyme that hydrolyzes $1 \mu \mathrm{mol}$ of pNPB per min at $\mathrm{pH} 7.0$ and $25^{\circ} \mathrm{C}$.

\subsubsection{Sugar esters production}

Sugar esters (or biosurfactants) were produced by esterification reactions. The synthesis experiments were conducted in flasks by adding oleic acid $(0.5 \mathrm{mmol})$; fructose, sucrose or lactose $(0.5 \mathrm{mmol})$; immobilized lipase $(22.5 \mathrm{mg})$; sodium sulfate anhydrous $(0.1 \mathrm{~g})$; ethanol $99 \%(0.6 \mathrm{~mL})$ and incubating the mixture at $40^{\circ} \mathrm{C}, 250 \mathrm{rpm}$ for $72 \mathrm{~h}$. In addition, control experiments were performed using the same procedures described in this section, without the incorporation of the lipase. This procedure has been previously described by Sabeder et al. (2006). At the end of the esterification reaction, the immobilized lipase, together with the sodium sulfate anhydrous (non reactive species), were removed by filtration using filter paper with a pore-size of $60-\mu \mathrm{m}$ (MachereyNagel Inc.). Afterward, the ethanol was evaporated from the reaction media using a rotoevaporator.

\subsubsection{Thin-layer chromatography (TLC)}

The obtained products (sugar esters) were identified by thinlayer chromatography (TLC), using commercial plates (Merck) coated with a $0.25 \mathrm{~mm}$ layer of silica gel (Khaled, Montet, Pina, \& Graille, 1991). A mixture of chloroform/hexane (1:1, v/v) was used for elution. Subsequently, the sugar esters spots were identified with iodine according to Ducret, Giroux, Trani, \& Lortie's (1995) work.

\subsubsection{Quantification of the sugar esters}

The sugar esters content was quantified by calculating the residual fatty acid amount in the reaction mixture, which was determined by the volumetric method described elsewhere (Leitgeb \& Knez, 1990). Briefly, $0.1 \mathrm{~g}$ of sample from the reaction mixture was diluted in $20 \mathrm{~mL}$ of $0.1 \mathrm{wt} \%$ phenolphthalein solution in absolute ethanol, and then titrated with standardized sodium hydroxide solution of $0.1 \mathrm{M}$ in water. The yield was calculated using equations (1)-(3)

$\frac{V_{\mathrm{NaOH}} * 0.1}{W_{\text {sample }}}=X$

$\frac{V_{\mathrm{NaOH}} * 0.1}{W_{\text {control }}}=X 1$

Yield $(\%)=100-\frac{X}{X 1} * 100$

where $V_{\mathrm{NaOH}}$ is the volume of sodium hydroxide, $W_{\text {sample }}$ is the weight of the sample and $W_{\text {control }}$ is the weight of the control. All measurements were performed in triplicate and results represent the means \pm standard deviation. 


\subsubsection{Preparation of fresh coconut milk and coconut milk emulsions}

Coconuts purchased in the local market (Fortaleza, CE, Brazil) were used for the extraction of coconut milk. The fresh coconut pulp was mixed with water $(3: 1 \mathrm{w} / \mathrm{v})$ in a domestic blender (Arno, France) for $5 \mathrm{~min}$. The resulting viscous exudate was filtered through cheesecloth to remove solids and obtain fresh coconut milk, according to methodology described by Seneviratne, Hapuarachchl, and Ekanayake (2009). Immediately after the extraction, surface tension, emulsification index and microscopic analysis of the fresh coconut milk were performed.

After extraction, appropriate amounts of sugar esters (produced according to Section 2.2.4) at different ratios, such as 1:1, 1:5, 1:10 and 1:100 (sugar ester: coconut milk, v/v), were added to the extracted milk, followed by stirring at high speed in a vortex for $2 \mathrm{~min}$ at room temperature (around $25^{\circ} \mathrm{C}$ ). Afterward, surface tension, emulsification index and microscopic analysis of the coconut milk emulsions were performed.

\subsubsection{Characterization of the coconut milk emulsions}

The coconut milk emulsions, formed by the stabilization of the extracted coconut milk with sugar esters (synthesized in this work), were characterized according to the techniques described below, surface tension, emulsification index and particle size distribution. Furthermore, samples of commercial coconut milk and fresh coconut milk were also characterized and results were compared to the ones achieved to fresh coconut milk with added sugar esters.

2.2.8.1. Surface tension. The surface tension was determined at room temperature $\left(25 \pm 1^{\circ} \mathrm{C}\right)$ by the Ring method as described elsewhere (Rodrigues, Teixeira, Van de Mei, \& Oliveira, 2006). A KRUSS Tensiometer (Kruss model K10) equipped with a $1.9 \mathrm{~cm}$ Du Nouy platinum ring was used. Measurements were done in quintuplicate and results represent the means \pm standard deviation.

2.2.8.2. Emulsification index. A $2 \mathrm{~mL}$ sample and $1 \mathrm{~mL}$ of $n$ hexadecane were homogenized using a vortex for $2 \mathrm{~min}$ at $25^{\circ} \mathrm{C}$. Next, the emulsion was left to settle for 2 min and the height of the emulsion was measured (T2). The index was calculated using equation (4).

Emulsion Index $(\%)=\frac{H_{e}}{H_{t}} * 100$

where $H_{e}$ is the height of the emulsification and $H_{t}$ is the total height of the liquid. The emulsions were left to settle also for 24 (T24) and $48 \mathrm{~h}$ (T48), in order to check its stability. All determinations were performed in triplicate and results represent the means \pm standard deviation (Cooper \& Goldenberg, 1987).

2.2.8.3. Determination of particle size distribution of coconut milk samples. Particle size distribution of commercial coconut milk, fresh coconut milk and fresh coconut milk with added sugar esters (produced according to Section 2.2.4) at different ratios, were determined by optical imaging and droplet size analysis using an optical microscope. One drop of the sample was transferred to the slide and a cover slip was placed over the sample. The samples were analyzed and identified using an Olympus model CH31 optical microscope (Southall, UK) with an attached camera and objective lens of $50 \times$ (for the fresh coconut milk) and $200 \times$ (for all other samples) with $1024 \times 720$ of resolution. The Image Pro 6.0 software (Olympus, UK Ltd.) was used to obtain the distribution and size of the particles in the samples. Furthermore, photographs were taken from typical fields to compare the changeability of the fat globules (Peamprasart \& Chiewchan, 2006).

\subsection{Statistical analysis and data analysis}

The data were statically evaluated using ANOVA and Tukey test at $95 \%$ of confidence level $(p=0.05)$. Origin Pro 8.1 software (OriginLab) was used for processing data.

\subsection{Immobilization parameters}

Immobilization yield (IY) was calculated by measuring the difference between enzyme hydrolytic activity on the supernatant before $\left(A t_{0}\right)$ and after $\left(A t_{f}\right)$ immobilization, according to equation (5)

$\mathrm{IY} \%=\frac{A t_{0}-A t_{f}}{A t_{0}} \times 100$

In this work, derivative activity $\left(A_{\mathrm{DER}}\right)$ is the hydrolytic activity determined as described before (Section 2.2.3). The recovered activity $\left(A_{\mathrm{REC}}\right)$ is defined as the ratio of apparent hydrolytic activity, obtained by the direct measure of derivative activity, and the difference between hydrolytic activity on the supernatant before and after immobilization, which can be considered as the derivative theoretical activity, see equation (6). Therefore, recovered activity can be considered as the biocatalyst effectiveness.

$A_{\mathrm{REC}}(\%)=\frac{A_{\mathrm{DER}}}{A t_{\mathrm{sup}}} \times 100$

where $A t_{\text {sup }}$ is the activity that disappeared on supernatant, that is to say

$A t_{\text {sup }}=A t_{0}-A t_{t}$

\section{Results and discussion}

\subsection{Properties of CALB immobilized on chitosan activated with} glycidol, ethylenediamine and glutaraldehyde

In this work, chitosan was used as a solid support for CALB immobilization, based on the methodology described by Rodrigues et al. (2008). Immobilization parameters were determined and derivative activity $\left(A_{\mathrm{DER}}\right)$, recovered activity $\left(A_{\mathrm{REC}}\right)$ and immobilization yield (IY) were, respectively, $5.73 \mathrm{U} / \mathrm{g}, 30.23 \%$ and 94.7\%. Theoretically, the use of EDA in the support activation procedure increases the distance between enzyme and support which may improve the enzyme access and, therefore, increases immobilization yield (Fernandez-Lafuente et al., 1993). High immobilization yields were achieved (IY $>90 \%$ ). Since a large amount of enzyme molecules disappeared from the supernatant, a higher enzyme load in the support was expected. However, derivative activity (less than $6 \mathrm{U} / \mathrm{g}$ ), and consequently recovered activity (around 30\%), was low, which may be explained by diffusion limitations and steric hindrance, since long space arms are generated during support activation. In the first case, the rate of hydrolysis reaction, used to determine activity, is governed not only by kinetics, but also it is influenced by the barrier that the substrate should pass to reach the active site of the enzyme. In many cases, the enzyme molecule itself acts as a barrier for diffusion (Gonçalves, Giordano, \& Giordano, 1997). The steric hindrance is characterized by the difficulty of access of the substrate molecule within the active site, since enzyme can be immobilized with a wrong orientation, obstructing the active site (Trevan, 1980). 


\subsection{Enzymatic synthesis of different sugar fatty acid esters with different biocatalysts}

Lipase from $C$. antarctica has been widely reported for the synthesis of sugar esters, being Habulin, Sabeder, and Knez (2008), Iwamoto, Shima, and Adachi (2008) and Pérez-Victoria and Morales (2007), some of the most recent examples. Moreover, chitosan is a good candidate for the immobilization of lipase when compared to other polysaccharides, namely, alginate and agarose. Therefore, CALB immobilized on acrylic resin (commercial biocatalyst Novozym 435) and chitosan were used to synthesize different sugar fatty acid esters at $40^{\circ} \mathrm{C}, 250 \mathrm{rpm}$, for $72 \mathrm{~h}$. Samples were taken from the reaction mixture and analyzed by thin-layer chromatography (TLC). It was possible to verify the presence of the desired sugar esters, namely fructose, sucrose and lactose esters, by measuring the retention factors (Rf). Fig. 1 illustrates an example of the TLCs obtained for the sugar esters synthesized.

The $\mathrm{Rf}$ values obtained for all sugar esters synthesized were found to be 0.5 , which is in accordance with previous reports. Khaled et al. (1991) and Tortorello \& Delwiche (1983) reported an Rf value of 0.51 for fatty acid esters. Therefore, it was possible to conclude that the desired sugar esters were obtained.

Table 1 presents the yields of sugar esters obtained from fructose, sucrose and lactose, by enzymatic synthesis using $C$. antarctica immobilized on different supports, namely acrylic resin and chitosan.

Although the yields of sugar esters achieved by using CALB immobilized on chitosan and acrylic resin were statistically different (at $5 \%$ level of probability), they are very close to each

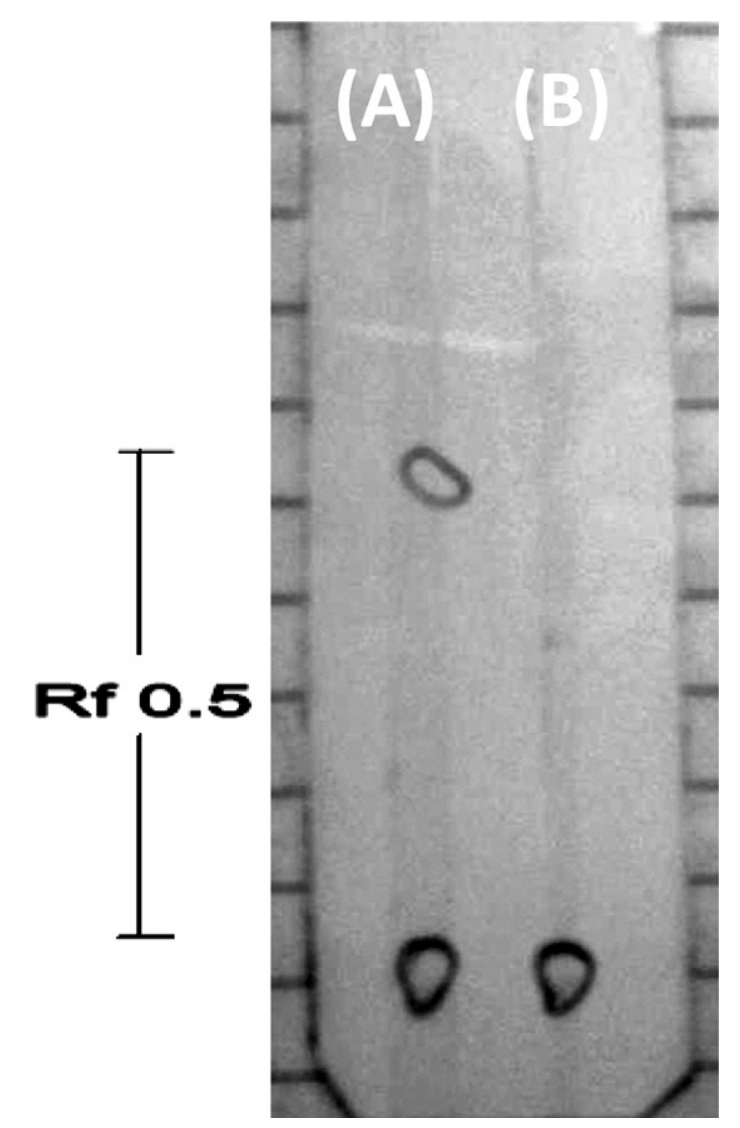

Fig. 1. Thin-layer chromatography of lactose ester. Lane (A) corresponds to the product synthesized at the given experimental conditions. Lane (B) corresponds to a control experiment where no enzyme was used, thus no sugar ester was formed.
Table 1

Sugar esters yields obtained by enzymatic synthesis catalyzed by immobilized lipase from $C$. antarctica type B (CALB).

\begin{tabular}{lll}
\hline Biocatalyst & Sugar esters & Yield $(\%) \pm \mathrm{SD}^{*}$ \\
\hline CALB-Acrylic resin & Fructose ester & $74.3 \pm 0.3^{\mathrm{a}}$ \\
CALB-Chitosan & & $70.1 \pm 0.0^{\mathrm{b}}$ \\
CALB-Acrylic resin & Sucrose ester & $56.1 \pm 0.2^{\mathrm{c}}$ \\
CALB-Chitosan & & $55.0 \pm 0.3^{\mathrm{d}}$ \\
CALB-Acrylic resin & Lactose ester & $83.6 \pm 0.3^{\mathrm{e}}$ \\
CALB-Chitosan & & $84.1 \pm 0.3^{\mathrm{f}}$ \\
\hline
\end{tabular}

$\mathrm{SD}=$ Standard deviation.

*Values with different letters in the same column present statistically significant differences $(p<0.05)$.

other when the same substrate was used, see Table 1. Yields were only 1.06-fold and 1.02-fold higher when Novozym 435 catalyzed the synthesis of fructose and sucrose ester, respectively. Yields achieved in this work were higher than the results reported by Sabeder et al. (2006). When CALB-chitosan catalyzed the synthesis of lactose ester, the yield was 1.01-fold higher than the result achieved by using the commercial biocatalyst. Based on the obtained results, CALB-chitosan is a suitable and efficient biocatalyst aiming at the production of sugar esters.

The lowest yield was obtained for the sucrose esters, Table 1 , while highest yields were achieved for the synthesis of lactose ester, independent of the biocatalyst used. Sucrose ester yields (>55.0\%) were higher than those found by Walsh, Bombyk, Wagh, Bingham, and Berreau (2009) using the same biocatalyst (20.9\%), but using vinyl laurate as substrate. Moreover, lactose ester yields in this work were much higher than the values that have been reported using other methods (Walsh et al., 2009; Wang, Wu, Wang, \& Lin, 2005; Wu, Wang, Xiao, Lu, \& Lin, 2004). Wu et al. (2004), for instance, achieved a yield of $62 \%$ in the enzymatic transesterification of several mono- and di-saccharides with divinyl dicarboxylates, ranging from 4 to 10 carbon atoms, catalyzed by an alkaline protease from Bacillus subtilis in pyridine. However, it is important to report that use of pyridine is not suitable in the food industry. In addition, Wang et al. (2005) obtained an ester yield of $77 \%$ using lactose and sucrose as substrate after transesterification with divinyl hexanedioate in anhydrous pyridine, catalyzed by an alkaline protease from $B$. subtilis at $50^{\circ} \mathrm{C}$. Walsh et al. (2009) reported values of $21.8 \%$ yield for lactose monolaurate utilizing C. antarctica lipase and 2-methyl-2-butanol as solvent.

Fructose ester yields in this work, above $70 \%$ (Table 1), were also higher than the results reported by Sabeder et al. (2006). These authors reported yields of fructose ester of $53 \%$ when using immobilized lipase SP 435 from C. antarctica B, and $44 \%$ of yield when using immobilized lipase SP 382 also from C. antarctica B.

\subsection{Characterization of the coconut milk emulsions produced by using the sugar esters synthesized enzymatically}

\subsubsection{Surface tension}

Table 2 presents the surface tension values determined for the coconut milk with added sugar esters (produced according to Section 2.2.4). The Tukey test was used at $95 \%$ probability to evaluate if there was a statistical significant difference between the surface tensions obtained for the different samples studied.

According to Table 2, for the fresh coconut milk with fructose ester in the ratios $1: 1$ and 1:5 (samples $A$ and $B$ ), and for the fresh coconut milk with sucrose ester in the same ratios (samples $E$ and $F$ ), no statistically significant differences were observed, suggesting that similar results could be obtained using a higher dilution, thus with less costs if a commercial application is envisaged. For the fresh coconut milk with lactose ester, this was not 
Table 2

Surface tension values measured for the fresh coconut milk, the commercial coconut milk and the fresh coconut milk with added sugar esters.

\begin{tabular}{|c|c|c|c|c|}
\hline \multirow[t]{2}{*}{ Groups } & \multirow[t]{2}{*}{ Products } & \multirow[t]{2}{*}{ Samples } & \multirow{2}{*}{$\begin{array}{l}\text { Sugar ester: } \\
\text { coconut } \\
\text { milk }(v / v)\end{array}$} & \multirow{2}{*}{$\frac{\text { Surface tension }}{\text { Mean }(\mathrm{N} / \mathrm{m}) \pm \mathrm{SD}^{*, \mathrm{e}, \mathrm{f}}}$} \\
\hline & & & & \\
\hline \multirow[t]{4}{*}{1} & Fresh coconut milk & A & $1: 1$ & $39.7 \pm 0.3^{\mathrm{a}}$ \\
\hline & with Fructose ester & B & $1: 5$ & $40.0 \pm 0.0^{\mathrm{a}, \mathrm{A}, 1}$ \\
\hline & & C & $1: 10$ & $41.1 \pm 0.2^{\mathrm{b}, \mathrm{c}, 3}$ \\
\hline & & $\mathrm{D}$ & $1: 100$ & $54.3 \pm 0.3^{c}$ \\
\hline \multirow[t]{4}{*}{2} & Fresh coconut milk & $\mathrm{E}$ & $1: 1$ & $40.2 \pm 0.3^{\mathrm{a}}$ \\
\hline & with Sucrose ester & $\mathrm{F}$ & $1: 5$ & $40.0 \pm 0.0^{\mathrm{a}, \mathrm{A}, 1}$ \\
\hline & & G & $1: 10$ & $41.9 \pm 0.2^{\mathrm{b}, \mathrm{D}, 4}$ \\
\hline & & $\mathrm{H}$ & $1: 100$ & $54.9 \pm 0.2^{c}$ \\
\hline \multirow[t]{4}{*}{3} & Fresh coconut milk & $\mathrm{I}$ & $1: 1$ & $38.0 \pm 0.0^{\mathrm{a}}$ \\
\hline & with Lactose ester & $\mathrm{J}$ & $1: 5$ & $39.2 \pm 0.3^{\mathrm{b}, \mathrm{B}, 2}$ \\
\hline & & $\mathrm{K}$ & $1: 10$ & $40.0 \pm 0.0^{\mathrm{c}, \mathrm{E}, 1,5}$ \\
\hline & & $\mathrm{L}$ & $1: 100$ & $52.1 \pm 0.2^{\mathrm{d}}$ \\
\hline \multirow[t]{2}{*}{4} & Fresh coconut milk & M & - & $52 \pm 0.3^{a}$ \\
\hline & $\begin{array}{l}\text { Commercial coconut } \\
\text { milk }\end{array}$ & $\mathrm{N}$ & - & $46 \pm 0.2^{b}$ \\
\hline
\end{tabular}

$\mathrm{SD}=$ Standard deviation.

*Values in each groups with letters different in the same column present significant difference $(p<0.05)$.

e Capital letters in the same column indicate comparison between the ratios 1:5 and $1: 10$, in each group.

f Superscript numbers indicate comparison in the ratios $1: 5$ and 1:10, between all groups.

observed since statistical significant differences were obtained for all the ratios studied.

Comparing the results obtained for all the sugar esters used, it was possible to verify that both fructose ester and sucrose ester at a ratio of $1: 5$ resulted in the same surface tension $(40.0 \mathrm{~N} / \mathrm{m})$. Using lactose ester, this surface tension value was obtained when a higher dilution $(1: 10)$ was used, thus meaning that this ester was more efficient in lowering the surface tension of the mixture.

From the results of the current study, it was found that the addition of each of the sugar esters lead to a significant reduction in surface tension of the fresh coconut milk. This is very important because the greater the ability of a sugar ester to reduce surface tension, the greater the emulsion stability formed in coconut milk (Akoh \& Nwosu, 1992). Results obtained with fresh coconut milk proved to be better than those found for the commercial coconut milk sample studied. It can be observed in Table 2 the addition of the lactose ester, for example, to fresh coconut milk reduced the surface tension from 52.0 to $38.0 \mathrm{~N} / \mathrm{m}$. Therefore, these results indicate the potential application of sugar esters in the preparation of milk coconut emulsions. To our knowledge this is the first report on the use of sugar esters to stabilize fresh milk coconut emulsions.

\subsubsection{Emulsification index (EI)}

Emulsification indexes (EI) determined for the same samples used for the surface tension measurements at different time points are gathered in Table 3.

An important parameter for evaluating the power of an emulsifier is the EI and the emulsion stability (Abu-Ruwaida, Banat, Haditirto, Salem, \& Kadri, 1991; Cooper \& Goldenberg, 1987; Singh, Van Hamme, \& Ward, 2007). All emulsions studied showed high EI values, above $49 \%$, for all the ratios sugar ester: coconut milk used (except for 1:100), as well as for all the time points accessed (2 min, 24 and $48 \mathrm{~h}$ ).

Comparing the results obtained for the different fructose ester: coconut milk ratios, Table 3 , the best condition studied was $1: 10$ for $24 \mathrm{~h}$ with an EI of 52.2\% (sample C), since it provides the highest EI at a lower concentration ratio. Emulsification indexes of $52.3 \%$ and $56.2 \%$ were obtained at a concentration ratio of $1: 5$ (the highest dilution for which the differences observed have statistical significance) and $48 \mathrm{~h}$ for sucrose and lactose ester, respectively. The surfactant head group size was varied when interchanging these sugars, since fructose is a monosaccharide, and the others (sucrose and lactose) are di-saccharides (Lehninger, Nelson, \& Cox, 1995). If the hydrophile-lipophile balance (HLB) system is considered (Attwood \& Florence, 1983), which presents values ranging from 0 to 20 on an arbitrary scale, the HLB number depends on group contributions. At this scale surfactants are classified as solubilizing agents, detergents, oil/water $(\mathrm{O} / \mathrm{W})$ or water/oil $(\mathrm{W} / \mathrm{O})$ emulsifiers and anti-foam agents, depending on the HLB number. Therefore, different surfactant head group sizes would lead to different HLB numbers and, consequently, to a surfactant with different characteristics. These facts may explain the variations observed in the Emulsification index (EI), but further experiments should be conducted in order to understand the achieved results.

For the food industry it is important and necessary to use emulsifiers that demonstrate low-cost and high stability of the emulsion obtained (Nitschke \& Costa, 2007). According to the results of the current work, the emulsifier that meets these characteristics is the lactose ester. In addition to achieving stability for a longer time (48 h), it has a high EI (54.1\%) at a low concentration ratio (1:10) (sample $\mathrm{K}$ ).

Moreover, even for concentration ratios of 1:10 of all sugar esters added to the fresh coconut milk, the results are superior to those found for samples using commercial coconut milk. To our

Table 3

Emulsification index (EI) determined for fresh coconut milk, commercial coconut milk and fresh coconut milk with added sugar esters.

\begin{tabular}{|c|c|c|c|c|c|c|}
\hline \multirow[t]{2}{*}{ Groups } & \multirow[t]{2}{*}{ Products } & \multirow[t]{2}{*}{ Samples } & \multirow{2}{*}{$\begin{array}{l}\text { Sugar esters: } \\
\text { coconut milk (v/v) }\end{array}$} & \multirow{2}{*}{$\frac{\text { After } 2 \mathrm{~min}}{\% \mathrm{EI} \pm \mathrm{SD}^{*}}$} & \multirow{2}{*}{$\frac{\text { After } 24 \mathrm{~h}}{\% \mathrm{EI} \pm \mathrm{SD}^{*}}$} & \multirow{2}{*}{$\frac{\text { After } 48 \mathrm{~h}}{\% \mathrm{EI} \pm \mathrm{SD}^{*}}$} \\
\hline & & & & & & \\
\hline \multirow[t]{4}{*}{1} & \multirow[t]{4}{*}{ Fresh coconut milk with Fructose ester } & A & $1: 1$ & $58.9 \pm 0.0^{\mathrm{a}}$ & $54.6 \pm 0.4^{\mathrm{a}}$ & $52.4 \pm 0.3^{\mathrm{a}}$ \\
\hline & & B & $1: 5$ & $58.1 \pm 0.2^{\mathrm{a}}$ & $53.2 \pm 0.9^{\mathrm{a}}$ & $50.2 \pm 0.2^{\mathrm{b}}$ \\
\hline & & $\mathrm{C}$ & $1: 10$ & $58.0 \pm 0.0^{\mathrm{a}}$ & $52.2 \pm 0.3^{\mathrm{a}}$ & $49.1 \pm 0.0^{c}$ \\
\hline & & $\mathrm{D}$ & $1: 100$ & $31.4 \pm 0.5^{\mathrm{b}}$ & $28.1 \pm 0.1^{\mathrm{b}}$ & $26.6 \pm 0.2^{\mathrm{d}}$ \\
\hline \multirow[t]{4}{*}{2} & \multirow[t]{4}{*}{ Fresh coconut milk with Sucrose ester } & $\mathrm{E}$ & $1: 1$ & $58.2 \pm 0.2^{\mathrm{a}}$ & $56.3 \pm 0.3^{\mathrm{a}}$ & $52.2 \pm 0.3^{\mathrm{a}}$ \\
\hline & & $\mathrm{F}$ & $1: 5$ & $58.2 \pm 0.2^{\mathrm{a}}$ & $55.4 \pm 0.1^{\mathrm{b}}$ & $52.3 \pm 0.1^{\mathrm{a}}$ \\
\hline & & G & $1: 10$ & $56.2 \pm 0.3^{\mathrm{b}}$ & $54.2 \pm 0.3^{c}$ & $51.1 \pm 0.0^{\mathrm{b}}$ \\
\hline & & $\mathrm{H}$ & $1: 100$ & $38.6 \pm 0.5^{\mathrm{c}}$ & $35.2 \pm 0.9^{\mathrm{d}}$ & $34.6 \pm 0.2^{\mathrm{c}}$ \\
\hline \multirow[t]{4}{*}{3} & \multirow[t]{4}{*}{ Fresh coconut milk with Lactose ester } & I & $1: 1$ & $60.5 \pm 0.9^{\mathrm{a}}$ & $58.3 \pm 0.9^{\mathrm{a}}$ & $56.4 \pm 0.3^{\mathrm{a}}$ \\
\hline & & $\mathrm{J}$ & $1: 5$ & $59.2 \pm 0.9^{\mathrm{b}}$ & $58.0 \pm 0.0^{\mathrm{a}}$ & $56.2 \pm 0.2^{\mathrm{a}}$ \\
\hline & & $\mathrm{K}$ & $1: 10$ & $58.2 \pm 0.2^{\mathrm{c}}$ & $56.3 \pm 0.3^{b}$ & $54.1 \pm 0.0^{\mathrm{b}}$ \\
\hline & & $\mathrm{L}$ & $1: 100$ & $36.7 \pm 0.3^{\mathrm{d}}$ & $34.4 \pm 0.3^{c}$ & $31.6 \pm 0.3^{c}$ \\
\hline \multirow[t]{2}{*}{4} & Fresh coconut milk & M & - & $37.2 \pm 0.5^{\mathrm{a}}$ & $33.4 \pm 0.0^{\mathrm{a}}$ & $29.6 \pm 0.3^{a}$ \\
\hline & Commercial coconut milk & $\mathrm{N}$ & - & $54.0 \pm 0.0^{\mathrm{b}}$ & $51.1 \pm 0.5^{\mathrm{b}}$ & $47.6 \pm 0.0^{\mathrm{b}}$ \\
\hline
\end{tabular}

$\mathrm{SD}=$ Standard deviation; \% $\mathrm{EI}=$ percentage of emulsification index (mean).

*Values in each groups with different letters in the same column present significant difference $(p<0.05)$. 
a



b

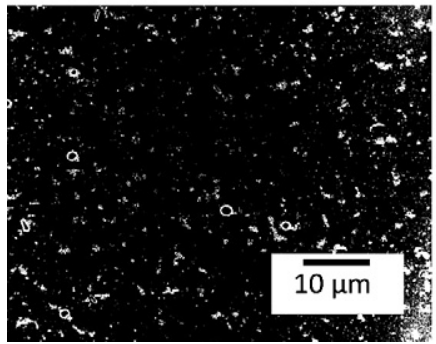

C

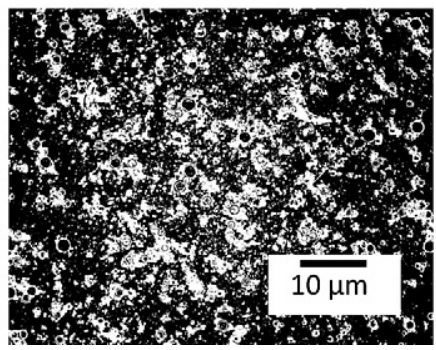

d

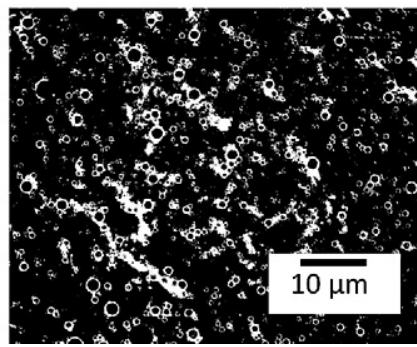

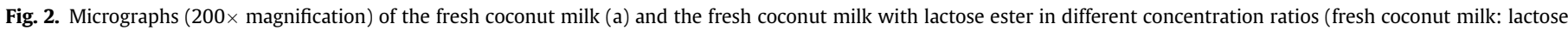
ester): 1:1 (b), 1:5 (c) and 1:10 (d).

knowledge this is the first report on emulsification indexes for mixtures of coconut milk with sugar esters.

\subsubsection{Particle size distribution}

The microstructures of the samples of coconut milk emulsion from different experimental conditions were examined using an optical microscope. Fig. 2 illustrates the structure of the fresh coconut milk and the fresh coconut milk containing lactose ester in different concentration ratios. Emulsions prepared with 1:100 biosurfactant:coconut milk presented high surface tension values, which are compared to the value measured for the fresh coconut milk. Therefore, those samples were not analyzed by optical imaging.
The micrographs taken from the emulsions obtained by using fresh coconut milk with fructose and sucrose esters showed similar structures (data not shown). Based on the results presented in Fig. 2, it was possible to determine the number of particles and their size distribution (Fig. 3). This information is important to investigate the effect of sugar ester on the stability of coconut milk emulsions. The freshly prepared coconut milk emulsion is expected to have large droplets and the reduction on particle size distribution is expected when small-molecule surfactants are added to the emulsion (Tangsuphoom \& Coupland, 2008).

In Figs. 2a and 3a, the presence of coconut fibers can be observed, which possess a variable size and are non-uniformly
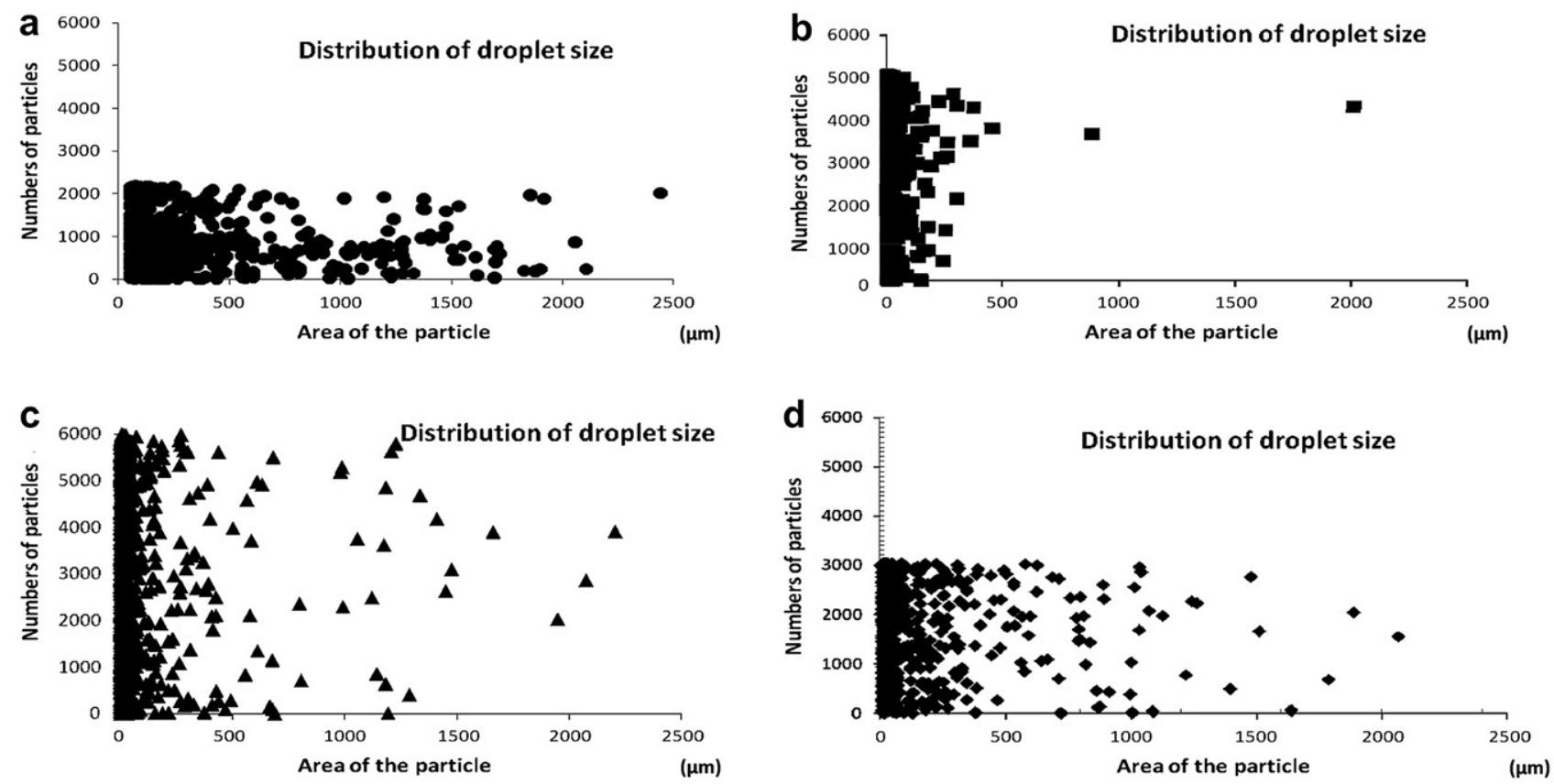

Fig. 3. Particle size distribution of the fresh coconut milk (a), the fresh coconut milk with lactose ester in different concentration ratios: $1: 1$ (b), $1: 5$ (c) and $1: 10$ (d). 
dispersed, showing some aggregates. These results are in accordance with the ones reported by Jirapeangtong et al. (2008).

Fig. 3b (ratio 1:1 of fresh coconut milk and lactose ester) showed that most of the droplets were sized between 0 and $10 \mu \mathrm{m}$, which explains the stability of the emulsion formed. Within this range of sizes, the probability of coalescence of the droplets is very low, since they are very small and uniform regarding the low volume of the dispersed phase. In the fresh coconut milk, the droplets were sized between 0 and $2000 \mu \mathrm{m}$ (Fig. 3a), indicating that the sugar ester added to form the emulsion was responsible for this stabilization. According to the literature (Tangsuphoom \& Coupland, 2008), the effective droplet diameter of coconut milk emulsions is reduced by the addition of small-molecule surfactants, since they are known to be able to displace proteins from the surface of emulsion droplets and disrupt flocs induced by the protein.

Fig. $3 c$ and d, showed a higher dispersion of the sugar ester globules in the aqueous phase, compared to Fig. 3b, indicating a lower stability of the product. Some authors (Seow \& Gwee, 1997; Tangsuphoom \& Coupland, 2009a) reported the use of chemical surfactants to stabilize coconut milk, namely SDS and Tween. Tangsuphoom \& Coupland (2009a) studied the effect of mixing chemical surfactants (SDS and Tween 20) with coconut milk under heat. Coconut milk emulsified with SDS was found to be stable in all heating treatments studied, meaning that no change in droplet size and no phase separation occurred. According to Seow \& Gwee (1997), polysorbates, such as Tween 20 and Tween 60, are widely used to improve the stability of sterilized coconut milk products, although typically at somewhat lower levels (around $0.3 \mathrm{wt} \%$ ) and in combination with gums.

Although some studies on the use of surfactants for the stabilization of coconut milk have been reported, to our knowledge this is the first report on the use of sugar esters for that purpose.

\section{Conclusions}

The enzymatic synthesis of fructose, sucrose and lactose esters was conducted using two different types of supports, acrylic resin and chitosan, for lipase immobilization. The enzyme immobilized on chitosan presented higher yields (84.1\%) in the production of lactose ester as compared to the acrylic resin support. Furthermore, the lactose ester showed a better performance regarding the decrease of fresh coconut milk surface tension and the stabilization of the emulsion as given by the emulsification index. The use of CALB immobilized on chitosan presents a promising alternative for the enzymatic production of sugar esters due to the possibility of enzyme reuse and economic viability.

\section{Acknowledgments}

The authors acknowledge the AlBan Programme (European Union Programme of High Level Scholarships for Latin America) for financial support of $\mathrm{N}$. Lopes through the research grant E07D401544BR. Furthermore, the authors acknowledge the Chemical Engineering Department - Federal University of Ceará (Campus of Pici - Brazil) and Biotechnology Laboratory - Federal University of Ceará for enabling the use of their laboratory facilities.

\section{References}

Abu-Ruwaida, A. S., Banat, I. M., Haditirto, S., Salem, A., \& Kadri, M. (1991). Isolation of biosurfactant producing bacteria - product, characterization, and evolution. Acta Biotecnologica, 2, 315-324.

Akoh, C. C., \& Nwosu, C. V. (1992). Emulsification properties of polyesters and sucrose ester blends II: alkyl glycoside polyesters. Journal of the American Oil Chemists' Society, 69, 14-19.
Attwood, D., \& Florence, A. T. (1983). Surfactants systems: Their chemistry, pharmacy and biology. London: Chapman and Hall. Chapter 8.

Bhatnagar, T., Boutaiba, S., Hacene, H., Cayol, J. L., Fardeau, M. L., Ollivier, B., et al. (2005). Lipolytic activity from Halobacteria: screening and hydrolase production. FEMS Microbiology Letters, 248, 133-140.

Cardias, H. C. T., Grininger, C. C., Trevisan, H. C., Guisan, J. M., \& Giordano, R. L. C. (1999). Influence of activation on the multipoint immobilization of penicillin C acylase on macroporous silica. Brazilian Journal of Chemical Engineering, 16 141-148.

Chamouleau, F., Coulon, D., Girardin, M., \& Ghoul, M. (2001). Influence of water activity and water content on sugar esters lipase-catalyzed synthesis in organic media. Journal of Molecular Catalysis B: Enzymatic, 11, 949-954.

Cooper, D. G., \& Goldenberg, B. G. (1987). Surface-active agents from two Bacillus species. Applied and Environmental Microbiology, 53, 224-229.

Ducret, A., Giroux, A., Trani, M., \& Lortie, R. (1995). Enzymatic preparation of biosurfactants from sugars or sugar alcohols and fatty acids in organic media under reduced pressure. Biotechnology and Bioengineering, 48, 214-221.

Fernandez-Lafuente, R., Rosell, C. M., Rodriguez, V., Santana, C., Soler, G., Batista, A. et al. (1993). Preparation of activated supports containing low pK amino groups. A new tool for protein immobilization via the carboxyl coupling method. Enzyme and Microbial Technology, 15, 546-550.

Gonçalves, L. R. B., Giordano, R. L. C., \& Giordano, R. C. (1997). Effects of diffusion on the kinetics of maltose hydrolysis using glucoamylase immobilized on macroporous silica. Brazilian Journal of Chemical Engineering, 14

Guisán, J. M. (1988). Aldehyde-agarose gels as activated supports for immobilizationstabilization of enzymes. Enzyme and Microbial Technology, 10, 375-382.

Habulin, M., Sabeder, S., \& Knez, Z. (2008). Enzymatic synthesis of sugar fatty acid esters in organic solvent and in supercritical carbon dioxide and their antimicrobial activity. The Journal of Supercritical Fluids, 45, 338-345.

Iwamoto, N., Shima, M., \& Adachi, S. (2008). Synthesis of xylitoyl fatty acid monoesters by immobilized lipase in subcritical acetone. Biochemical Engineering Journal, 38, 16-21.

Jena, S., \& Das, H. (2006). Modeling of particle size distribution of sonicated coconut milk emulsion: effect of emulsifiers and sonication time. Food Research International, 39, 606-611.

Jirapeangtong, K., Siriwatanayothin, S., \& Chiewchan, N. (2008). Effects of coconut sugar and stabilizing agents on stability and apparent viscosity of high-fat coconut milk. Journal of Food Engineering, 87, 422-427.

Khaled, N., Montet, D., Pina, M., \& Graille, J. (1991). Fructose oleate synthesis in a fixed catalyst bed reactor. Biotechnology Letters, 13, 167-172.

Lehninger, A. L., Nelson, A. L., \& Cox, M. M. (1995). Principles of biochemistry (2nd ed.). New York: Longman. Chapter 11.

Leitgeb, M., \& Knez, Z. (1990). The influence of water on the synthesis of n-butyl oleate by immobilized mucor miehei lipase. Journal of the American Oil Chemists' Society, 67, 775-778.

Nitschke, M., \& Costa, S. G. V. A. O. (2007). Biosurfactants in food industry. Trends in Food Science \& Technology, 18, 252-259.

Onsaard, E., Vittayanont, M., Srigam, S., \& McClements, D. J. (2005). Properties of oilin-water emulsions stabilized by coconut skim milk proteins. Journal of Agricultural and Food Chemistry, 53, 5747-5753.

Park, D., Haam, S., Ahn, I., Lee, T. G., Kim, H., \& Kim, W. (2004). Enzymatic esterification of $\beta$-methylglucoside with acrylic/methacrylic acid in organic solvents. Journal of Biotechnology, 107, 151-160.

Peamprasart, T., \& Chiewchan, N. (2006). Effect of fat content and preheat treatment on the apparent viscosity of coconut milk after homogenization. Journal of Food Engineering, 77, 653-658.

Pérez-Victoria, I., \& Morales, J. C. (2007). One- and two-step enzymatic synthesis of polymerizable vinyladipoyl mono- and diesters of non-reducing trisaccharides. Journal of Molecular Catalysis B: Enzymatic, 48, 8-15.

Rodrigues, D. S., Mendes, A. A., Adriano, W. S., Gonçalves, L. R. B., \& Giordano, R. L. C. (2008). Multipoint covalent immobilization of microbial lipase on chitosan and agarose activated by different methods. Journal of Molecular Catalysis B: Enzymatic, 51, 100-109.

Rodrigues, L. R., Teixeira, J. A., Van de Mei, H. C., \& Oliveira, R. (2006). Isolation and partial characterization of a biosurfactant produced by Streptococcus thermophilus A. Colloid Surface B: Biointerfaces, 53, 105-112.

Sabeder, S., Habulin, M., \& Knez, Z. (2005). Comparison of the esterification of fructose and palmitic acid in organic solvent and in supercritical carbon dioxide. Industrial \&' Engineering Chemistry Research, 44, 9631-9635.

Sabeder, S., Habulin, M., \& Knez, Z. (2006). Lipase-catalyzed synthesis of fatty acid fructose esters. Journal of Food Engineering, 77, 880-886.

Seneviratne, K. N., Hapuarachchl, C. D., \& Ekanayake, S. (2009). Comparison of the phenolic-dependent antioxidant properties of coconut oil extracted under cold and hot conditions. Food Chemistry, 114, 1444-1449.

Seow, C. C., \& Gwee, C. N. (1997). Coconut milk: chemistry and technology. International Journal of Food Science and Technology, 32, 189-201.

Singh, A., Van Hamme, J. D., \& Ward, O. P. (2007). Surfactants in microbiology and biotechnology. Part 2. Application aspects. Biotechnology Advances, 25 99-121.

Tangsuphoom, N., \& Coupland, J. N. (2005). Effect of heating and homogenization on the stability of coconut milk emulsions. Journal of Food Science E: Food Engineering and Physical Properties, 70, 466-470.

Tangsuphoom, N., \& Coupland, J. N. (2008). Effect of surface-active stabilizers on the microstructure and stability of coconut milk emulsions. Food Hydrocolloids, 22, 1233-1242 
Tangsuphoom, N., \& Coupland, J. N. (2009a). Effect of thermal treatments on the properties of coconut milk emulsions prepared with surface-active stabilizers. Food Hydrocolloids, 23, 1792-1800.

Tangsuphoom, N., \& Coupland, J. N. (2009b). Effect of surface-active stabilizers on the surface properties of coconut milk emulsions. Food Hydrocolloids, 23 , 1801-1809.

Tortorello, M. L., \& Delwiche, E. A. (1983). Utilization of fructose and ribose in lipopolysaccharide synthesis by Veillonella parvula. Infection and Immunity, 41 423-425.

Trevan, M. D. (1980). Immobilized enzymes (1st ed.). England: John Wiley \& Sons Ltd.

Tsavas, P., Polydorou, S., Faflia, I., Voutsas, E. C., Tassios, D., Flores, M. V., et al. (2002) Solubility of glucose in mixtures containing $t$-pentanol, dimethylsulfoxide acids, esters and water. Journal of Chemical and Engineering Data, 47, 807-810.
Walsh, M. K., Bombyk, R. A., Wagh, A., Bingham, A., \& Berreau, L. M. (2009). Synthesis of lactose monolaurate as influenced by various lipases and solvents. Journal of Molecular Catalysis B: Enzymatic, 60, 171-177.

Wang, X., Wu, Q., Wang, N., \& Lin, X. F. (2005). Chemo-enzymatic synthesis of disaccharide-branched copolymers with high molecular weight. Carbohydrate Polymers, 60, 357-362.

Wu, Q., Wang, N., Xiao, Y. M., Lu, D. S., \& Lin, X. F. (2004). Regiospecific alkaline protease-catalyzed divinyl acyl transesterifications of primary hydroxyl groups of mono- and di-saccharides in pyridine. Carbohydrate Research, 339, 2059-2067.

Ye, R., Pyo, S. H., \& Hayes, D. G. (2010). Lipase-catalyzed synthesis of saccharide-fatty acid esters using suspensions of saccharide crystals in solvent-free media. Journal of the American Oil Chemists' Society, 87, 281-293. 